\title{
Pyroptosis, a novel mechanism implicated in cataracts
}

\author{
$\mathrm{XIN} \mathrm{JIN}^{1}$, HAO JIN ${ }^{2}$, YAN SHI ${ }^{1}$, YIYUAN GUO ${ }^{1}$ and HONG ZHANG ${ }^{1}$ \\ Departments of ${ }^{1}$ Ophthalmology and ${ }^{2}$ Orthopedics, The First Affiliated Hospital of Harbin Medical University, \\ Harbin, Heilongjiang 150001, P.R. China
}

Received November 15, 2016; Accepted June 27, 2017

DOI: $10.3892 / \mathrm{mmr} .2018 .9188$

\begin{abstract}
An understanding of the mechanism of cataract formation may reduce its burden on medical care worldwide. It is established that pyroptosis is associated with oxidative stress, one of the causes of cataracts, and may provide novel therapeutic targets for the treatment of cataracts. The present study therefore investigated the role of pyroptosis in cataract formation. SRA01/04 human lens epithelium cells (HLECs) were treated with $\mathrm{H}_{2} \mathrm{O}_{2}$ and cell viability was assessed by an MTT assay. Pyroptosis in HLECs was examined by TUNEL staining, and the expression of caspase- 1 and interleukin(IL)- $1 \beta$ was determined using reverse transcription-quantitative polymerase chain reaction (RT-qPCR), western blot analysis and immunostaining. A caspase-1 inhibitor was used to investigate the effects of caspase-1 downregulation. In addition, the expression of caspase- 1 and IL- $1 \beta$ in lens anterior capsule tissue samples from patients with cataracts and normal controls was also analyzed by immunostaining, RT-qPCR and western blot analysis. The results demonstrated that pyroptosis in $\mathrm{H}_{2} \mathrm{O}_{2}$-treated HLECs, and the mRNA and protein expression of caspase- 1 and IL-1 $\beta$, was significantly increased compared with control cells. Furthermore, caspase- 1 and IL-1 $\beta$ expression was significantly increased in cataract tissue samples compared with normal controls. When HLECs were cotreated with a caspase- 1 inhibitor and $100 \mu \mathrm{M} \mathrm{H}_{2} \mathrm{O}_{2}$, caspase- 1 and IL-1 $\beta$ expression were decreased compared with the $100 \mu \mathrm{M}$ $\mathrm{H}_{2} \mathrm{O}_{2}$-only group. In conclusion, the results of the present study demonstrate that pyroptosis may have a role in cataract formation, and the caspase- 1 and IL-1 $\beta$ pathways may be
\end{abstract}

Correspondence to: Professor Hong Zhang, Department of Ophthalmology, The First Affiliated Hospital of Harbin Medical University, 23 Youzheng Road, Harbin, Heilongjiang 150001, P.R. China

E-mail: hydggzh@163.com

Abbreviations: HLECs, human lens epithelium cells; FBS, fetal bovine serum; DMEM, Dulbecco's modified Eagle's medium; RT-qPCR, reverse transcription-quantitative polymerase chain reaction; ROS, reactive oxygen species

Key words: pyroptosis, cataracts, caspase-1, interleukin-1 $\beta$ involved in this pathological process. Pyroptosis appears to be a promising target in the prevention of cataract formation.

\section{Introduction}

As a global problem, cataracts are the leading cause of blindness in the elderly population and account for almost half of visually disabled people (1). Surgery has become an effective treatment method for cataracts. However, risks of surgical complications exist $(2,3)$. Understanding the mechanisms of cataracts may allow the development of cataracts to be prevented, and subsequently reduce risks of surgical complications and the burden of cataracts on medical care worldwide.

In recent decades, emerging research has enriched our molecular understanding of the various forms of programmed cell death, which includes several endogenous genetically defined pathways (4). Apoptosis is the most widely recognized form of programmed cell death and involves particular caspases (cysteine-dependent aspartate-specific proteases), which lead to coordinated cell disassembly $(5,6)$. It has been established that apoptosis of lens epithelial cells is a common cellular basis for the initiation and progression for non-congenital cataracts (7). Additional forms of programmed cell death include autophagy, oncosis and pyroptosis (also termed caspase 1-dependent programmed cell death) (8).

Pyroptosis is associated with rapid plasma membrane rupturing and the release of proinflammatory intracellular contents (9), and may be initiated by numerous pathological stimuli, including brain injury (10), myocardial infarction (11) or cancer (12), and has an important function in the control of microbial infections (13). Pyroptosis is closely associated with oxidative stress $(14,15)$. Several studies have demonstrated that oxidative stress has a key role in cataractogenesis in vivo and in vitro $(16,17)$. However, whether pyroptosis is implicated in the initiation and progression of non-congenital cataracts remains to be established.

The present study investigated the involvement of pyroptosis in cataract formation in a human lens epithelium cell line, and also characterized the expression of caspase- 1 and interleukin (IL)-1 $\beta$ in cataract lens anterior capsule tissue samples.

\section{Materials and methods}

Materials. The SV40 T-antigen-transformed human lens epithelial cell line (SRA01/04 cells) was obtained from the American Type Culture Collection (Manassas, VA, USA). 
Fetal bovine serum (FBS) and Dulbecco's modified Eagle's medium/F12 (DMEM/F12) were obtained from Biological Industries (Kibbutz Beit-Haemek, Israel). $\mathrm{H}_{2} \mathrm{O}_{2}$ was purchased from Shanghai Zhongshi Chemistry Industry Co., Ltd. (Shanghai, China). MTT was purchased from Sigma-Aldrich (Merck KGaA, Darmstadt, Germany). TRIzol and polymerase chain reaction (PCR) primers were purchased from Invitrogen (Thermo Fisher Scientific, Inc., Waltham, MA, USA). The NanoDrop spectrophotometer was obtained from NanoDrop Technologies (Thermo Fisher Scientific, Inc.). Primary antibodies were purchased from Santa Cruz Biotechnology, Inc. (Dallas, TX, USA). Fluorochrome-labeled secondary antibody (Alexa Fluor 800) was obtained from Thermo Fisher Scientific, Inc.

Human tissue samples. A total of 40 cataract lens anterior capsule samples were obtained from patients with cataracts that were free from other types of ocular diseases (age range, 68-80 years) in the operation room of the Eye Hospital of Harbin Medical University (Harbin, China), between October 2015 and March 2016. In addition, 40 control lens anterior capsular samples were collected from healthy donor eyes (age range, 54-69 years) that were free of any ocular diseases and donated to the Eye Bank of Heilongjiang Province (Harbin, China), between July 2014 to March 2016. Samples were either embedded in paraffin or immediately snap-frozen and stored at $-80^{\circ} \mathrm{C}$ until RNA extraction. All samples were collected with informed consent and the study was approved by the Research Ethics Committee of Harbin Medical University. Patient information is listed in Table I.

Cell culture. SRA01/04 cells $\left(1 \times 10^{5}\right)$ were cultured in DMEM/F12 supplemented with $20 \% \mathrm{FBS}$ at $37^{\circ} \mathrm{C}$ in $5 \% \mathrm{CO}_{2}$ overnight. Cells in the logarithmic growth phase were collected and treated with $0,25,50$ or $100 \mu \mathrm{M} \mathrm{H}_{2} \mathrm{O}_{2}$ for 0,24 or $48 \mathrm{~h}$ at $37^{\circ} \mathrm{C}$ in $5 \% \mathrm{CO}_{2}$. Control cells were treated with DMEM/F12 containing 20\% FBS alone. Caspase-1 inhibitor for downregulation was synthesized by Cayman Chemical Company (item no. 10014; Ann Arbor, MI, USA). After the cell density reached $80 \%, 100 \mu \mathrm{M}$ caspase-1 inhibitor was added simultaneously with $\mathrm{H}_{2} \mathrm{O}_{2}$ to the designated well. After 0,24 or $48 \mathrm{~h}$ of treatment at $37^{\circ} \mathrm{C}$, cells were harvested for subsequent experiments.

Cell proliferation assay. MTT were used in accordance with the manufacturer's protocol. SRA01/04 cells were seeded in 96-well plates at $1 \times 10^{4}$ cells/well and treated with $0,25,50$, 100 or $200 \mu \mathrm{M} \mathrm{H}_{2} \mathrm{O}_{2}$ and maintained for 24 or $48 \mathrm{~h}$ at $37^{\circ} \mathrm{C}$. MTT solution $(10 \mu \mathrm{l})$ was added to each well and cells were incubated in $37^{\circ} \mathrm{C}$ for $2 \mathrm{~h}$. DMSO $(150 \mu \mathrm{l})$ was added to each well. The absorbance at a wavelength of $450 \mathrm{~nm}$ was evaluated using a microplate reader. The data are representative of three individual experiments in triplicate.

Reversetranscription-quantitative PCR (RT-qPCR). Caspase-1 and IL-1 $\beta$ mRNA expression was determined by RT-qPCR using SYBR Green detection reagents. Primer sequences are listed in Table II. Total RNA was extracted from each sample with TRIzol reagent, according to the manufacturer's protocol. Total isolated RNA (500 ng) was used to synthesize cDNA in a $20 \mu 1$ reaction mixture containing $2 \mu \mathrm{l}$ RNA, $4 \mu 15 \mathrm{X}$ RT buffer, $1 \mu \mathrm{l}$ primer mix, $1 \mu \mathrm{l}$ RT enzyme and $12 \mu \mathrm{l} \mathrm{H}_{2} \mathrm{O}$ (Toyobo Life Science, Osaka, Japan). qPCR amplification was performed in a $20 \mu \mathrm{l}$ reaction volume containing $2 \mu \mathrm{l} \mathrm{cDNA}$, $6 \mu 1$ diethyl pyrocarbonate, $10 \mu \mathrm{l} \mathrm{SYBR}$ Master mix (Toyobo Life Science), $1 \mu \mathrm{l}$ forward primer and $1 \mu \mathrm{l}$ reverse primer. qPCR was performed using the ABI PRISM 7500 Sequence Detection System (Applied Biosystems; Thermo Fisher Scientific, Inc.) and PCR conditions were as follows: $95^{\circ} \mathrm{C}$ for $60 \mathrm{sec}$, followed by 40 cycles of $95^{\circ} \mathrm{C}$ for $15 \mathrm{sec}, 60^{\circ} \mathrm{C}$ for $15 \mathrm{sec}$ and $72^{\circ} \mathrm{C}$ for $45 \mathrm{sec}$. The housekeeping gene GAPDH was used as an internal positive control standard for quantitative analysis in triplicate. Cq values obtained via the $2^{-\Delta \Delta \mathrm{Cq}}$ method (18) were used to quantify mRNA expression.

Western blot analysis. Western blot analysis was performed to detect the expression levels of certain proteins of interest. Samples were lysed using radioimmunoprecipitation assay buffer (Beijing Solarbio Science \& Technology Co., Ltd., Beijing, China). A bicinchoninic acid assay (Beijing Solarbio Science \& Technology Co., Ltd.) was used to determine the protein concentration of the samples. Protein $(50 \mu \mathrm{g})$ per sample was separated using 10\% SDS-PAGE and transferred onto nitrocellulose membranes. Membranes were blocked in 5\% milk for $2 \mathrm{~h}$ at room temperature, and then immunoblotted overnight with rabbit caspase-1 $(1: 1,000$; cat. no. PRS3459; Sigma-Aldrich; Merck KGaA), IL-1 $\beta$ (1:1,000; cat. no. SAB4503272; Sigma-Aldrich; Merck KGaA) and GAPDH (1:800; cat no. ab8245; Abcam, Cambridge, UK) primary antibodies at $4^{\circ} \mathrm{C}$ with gentle shaking. Subsequently, membranes were incubated with goat anti-rabbit fluorochrome-labeled secondary antibody for $2 \mathrm{~h}$ at room temperature (1:5,000; Alexa Fluor 800; cat. no. A32735). Immunoreactivity was detected with an Odyssey fluorescent scanning system (LI-COR Biosciences, Lincoln, NE, USA) and analyzed by Image Studio software version 4.0 (LI-COR Biosciences). GAPDH was used as loading control.

Immunofluorescence and immunohistochemistry staining. For immunofluorescence staining, SRA01/04 cells were seeded in 24-well plates at a density of $3 \times 10^{5}$ cells/well and maintained for $24 \mathrm{~h}$. Following treatment with $100 \mu \mathrm{M} \mathrm{H}_{2} \mathrm{O}_{2}$ with or without caspase-1 inhibitor treatment, cells were fixed with $4 \%$ paraformaldehyde for $1 \mathrm{~h}$ at $37^{\circ} \mathrm{C}$, then permeabilized with $0.1 \%$ Triton for $15 \mathrm{~min}$ at room temperature. After rinsing with PBS, cells were blocked with $10 \%$ bovine serum albumin (Biosharp, China) $30 \mathrm{~min}$ at room temperature. The cells were subsequently incubated with rabbit caspase-1 $(1: 200)$ or IL-1 $\beta$ (1:200) antibodies overnight at $37^{\circ} \mathrm{C}$. Cells were rinsed three times in PBS and incubated with $\mathrm{Cy} 3$-conjugated goat anti-rabbit IgG (1:100; cat. no. AP132C; Sigma-Aldrich; Merck KGaA) secondary antibody $30 \mathrm{~min}$ at room temperature. Staining was observed using an Observer A1 fluorescence microscope (Zeiss GmbH, Jena, Germany), and ZEN software version 2 (Zeiss $\mathrm{GmbH}$ ) was used.

For immunohistochemistry staining, lens anterior capsule tissue samples were placed on cover slides and fixed with $4 \%$ paraformaldehyde for $30 \mathrm{~min}$ at room temperature. After rinsing with PBS, capsular samples were penetrated with $0.1 \%$ Triton X-100 15 min and blocked with 5\% BSA 30 min at room 
Table I. Patient and volunteer information.

\begin{tabular}{|c|c|c|c|c|}
\hline Tissue sample type & Mean age, years $( \pm S D)$ & Age range, years & Males (\%) & Females $(\%)$ \\
\hline Cataracts, $n=40$ & $74.4( \pm 3.84)$ & $68-80$ & $17(42.5)$ & $23(57.5)$ \\
\hline Normal, $n=40$ & $62.4( \pm 4.04)$ & $54-69$ & $20(50)$ & $20(50)$ \\
\hline
\end{tabular}

$\mathrm{SD}$, standard deviation.

Table II. Primers used for reverse transcription-quantitative polymerase chain reaction.

Primer sequence

\begin{tabular}{lll}
\cline { 2 - 3 } Gene & \multicolumn{1}{c}{ Forward } & \multicolumn{1}{c}{ Reverse } \\
\hline GAPDH & 5'-AAGAAGGTGGTGAAGCAGGC-3' & 5'-TCCACCACCCTGTTGCTGTA-3' \\
Caspase-1 & 5'-ACACGTCTTGCCCTCATTATCT-3' & 5'-ATAACCTTGGGCTTGTCTTTCA-3' \\
Interleukin-1 $\beta$ & 5'-CCTTGTCGAGAATGGGCAGT-3' & 5'-TTCTGTCGACAATGCTGCCT-3'
\end{tabular}

temperature. Slides were subsequently incubated with primary antibodies against caspase-1 (1:200) and IL-1 $\beta(1: 200)$ at $4^{\circ} \mathrm{C}$ overnight. Slides were then washed using PBS and further incubated with secondary antibodies conjugated to Cy3 (1:100; cat no. AP132C; Sigma-Aldrich; Merck KGaA) for $2 \mathrm{~h}$ at room temperature, followed by staining with 3,3'-diaminobenzidine $15 \mathrm{sec}$ at room temperature. Samples were hydrated in graded ethanol. Staining was observed using an Observer A1 fluorescence microscope (Zeiss GmbH, Jena, Germany), and ZEN software version 2 (Zeiss $\mathrm{GmbH}$ ) was used.

TUNEL staining. SRA01/04 cells $\left(3 \times 10^{5}\right.$ cells/well) were plated onto coverslips in 24-well culture plates and an in situ Cell Death Detection kit (Fluorescein; Roche, Diagnostics; Indianapolis, IN, USA) was employed to detect DNA fragmentation of individual cells, according to the manufacturer's protocol. The nuclei were stained with DAPI $(1 \mu \mathrm{g} / \mathrm{ml})$ for $5 \mathrm{~min}$ at room temperature. TUNEL staining was assessed by fluorescence microscopy (Eclipse 80i; Nikon Co., Tokyo, Japan) at x200 magnification in 6 fields of view. Nuclei that were double labeled with DAPI and TUNEL were considered positive.

Statistical analysis. Statistical significance was determined by a two-tailed Student's t-test or one-way analysis of variance followed by Tukey's post hoc test. Data are presented as the mean \pm standard deviation. The results were analyzed by SPSS 18.0 software (SPSS, Inc., Chicago, IL, USA) and $\mathrm{P}<0.05$ was considered to indicate a statistically significant difference.

\section{Results}

Pyroptosis is induced in $\mathrm{H}_{2} \mathrm{O}_{2}$-treated SRA01/04 cells. Caspase-1 and IL-1 $\beta$ are established markers of pyroptosis. To determine whether pyroptosis is involved in cataract formation, SRA01/04 lens epithelial cells were exposed to various concentrations of $\mathrm{H}_{2} \mathrm{O}_{2}(0,25,50$ and $100 \mu \mathrm{M})$ for 24 or 48 h. Pyroptosis was detected by morphology analyses, MTT, RT-qPCR and western blot assays, and TUNEL staining
(Figs. 1 and 2, respectively). SRA01/04 cells became swollen and the cell number decreased with increasing $\mathrm{H}_{2} \mathrm{O}_{2}$ concentration. MTT assay results demonstrate that SRA01/04 cell growth was inhibited by 25, 50, 100 and $200 \mu \mathrm{M} \mathrm{H}_{2} \mathrm{O}_{2}$ at 24 and 48 h (Fig. 1B). The mRNA and protein expression of caspase- 1 and IL- $1 \beta$ were increased in $\mathrm{H}_{2} \mathrm{O}_{2}$-treated SRA01/04 cells in a dose-dependent manner (Fig. 1C-F). Compared with the control group, relative caspase- 1 and IL-1 $\beta$ expression increased $>50 \%$ when the $\mathrm{H}_{2} \mathrm{O}_{2}$ concentration was $100 \mu \mathrm{M}$. Furthermore, TUNEL assay results provided further evidence that $\mathrm{H}_{2} \mathrm{O}_{2}$-induced cell pyroptosis was significantly increased in a dose-dependent manner (Fig. 2). Based on these results, $100 \mu \mathrm{M} \mathrm{H}_{2} \mathrm{O}_{2}$ was selected for subsequent experiments.

Validation of pyroptosis in the lens anterior capsules of patients with cataracts. To further validate these results, cataract lens anterior capsules and normal lens anterior capsule samples were collected and analyzed for caspase- 1 and IL-1 $\beta$ expression using immunohistochemistry staining, RT-qPCR and western blot analysis. Immunohistochemistry staining results demonstrated increased positive staining of caspase-1 and IL-1 $\beta$ in the cataract lens anterior capsular specimens compared with normal samples (Fig. 3A). The mRNA and protein expression levels of caspase- 1 and IL-1 $\beta$ were also significantly upregulated in cataract samples compared with normal anterior lens capsules (Fig. 3B-E).

Caspase-1 inhibitor reduces pyroptosis in SRA01/04 cells. To confirm the role of caspase-1 in pyroptosis in SRA01/04 cells, caspase-1 was downregulated by an irreversible inhibitor. Caspase-1 inhibitor was incubated with SRA01/04 cells and the efficacy was confirmed by immunofluorescence staining, RT-qPCR and western-blot analysis (Fig. 4A-C). In addition, pyroptosis was significantly reduced by caspase-1 inhibitor treatment compared with the $100 \mu \mathrm{M} \mathrm{H}_{2} \mathrm{O}_{2}$-only group, as demonstrated by TUNEL staining (Fig. 4D). Furthermore, the mRNA and protein expression of IL-1 $\beta$, which functions downstream of caspase-1, was significantly decreased in 
A

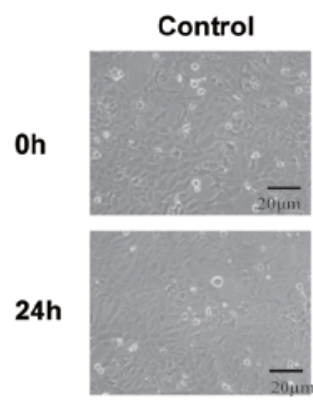

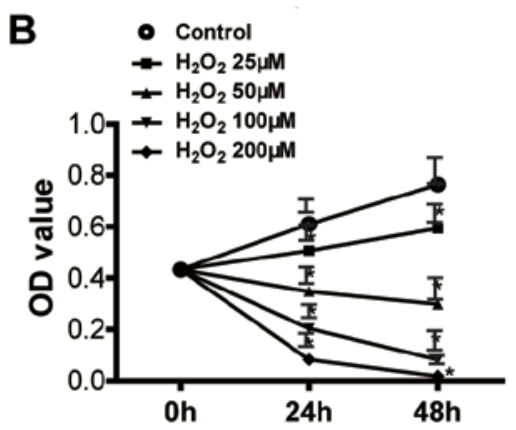

E

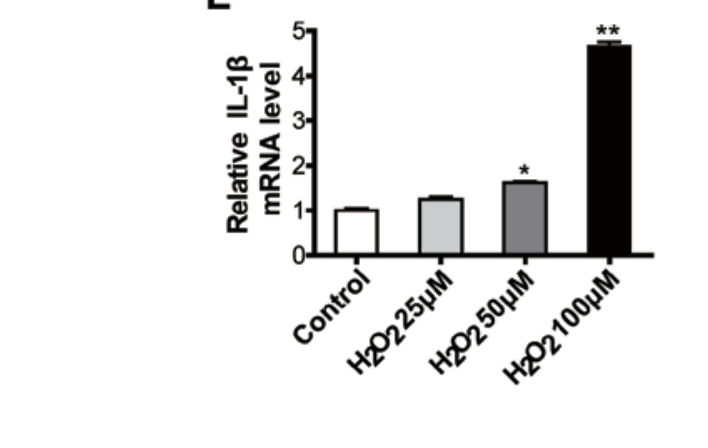

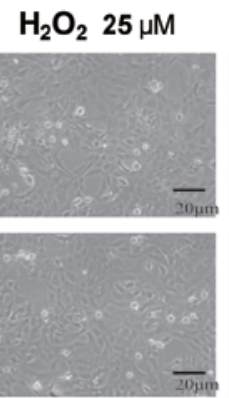

C

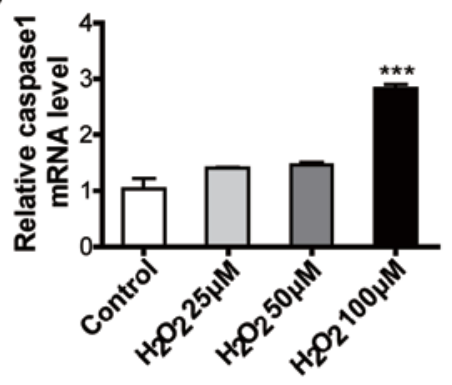

$\mathrm{H}_{2} \mathrm{O}_{2} 100 \mu \mathrm{M}$
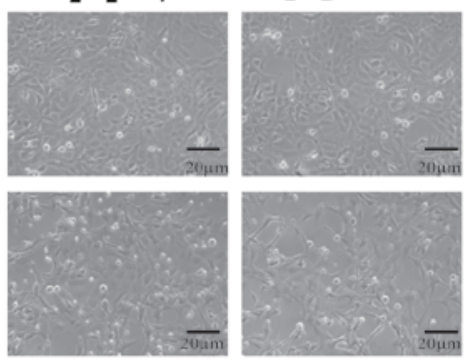

D

$\mathbf{F}$

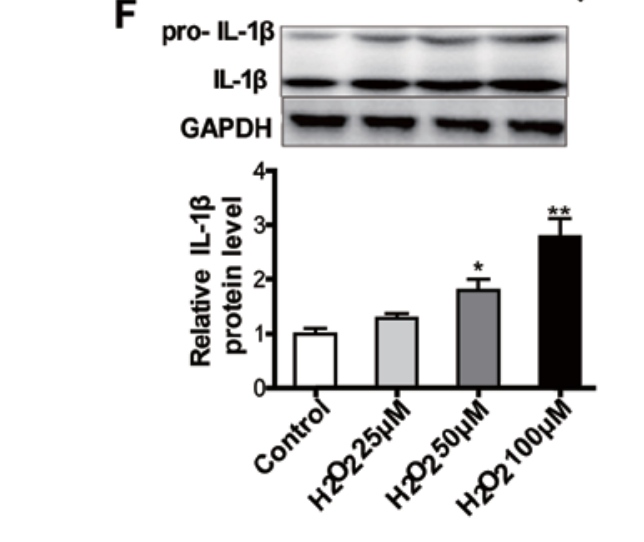

Cl.caspase1

GAPDH

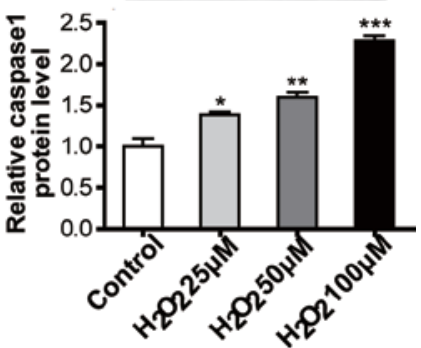

सर्थर सी सर्थ
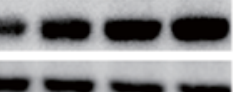

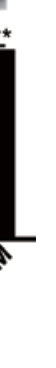

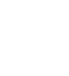

Figure 1. Pyroptosis was increased in $\mathrm{H}_{2} \mathrm{O}_{2}$ treated human lens epithelium cells. (A) When exposed to $0,25,50$ and $100 \mu \mathrm{M} \mathrm{H}_{2} \mathrm{O}_{2}$ for 24 h, $\mathrm{SRA} 01 / 04$ cells became swollen and the cell number decreased with increasing $\mathrm{H}_{2} \mathrm{O}_{2}$ concentration. Scale bar, $20 \mu \mathrm{m}$. x200 magnification. (B) MTT assay results demonstrated that SRA01/04 cell growth was inhibited when treated with 25, 50, 100 and $200 \mu \mathrm{M} \mathrm{H}_{2} \mathrm{O}_{2}$ for 24 and $48 \mathrm{~h}$. (C) RT-qPCR results indicated that relative caspase-1 mRNA levels were increased with increasing concentrations of $\mathrm{H}_{2} \mathrm{O}_{2}$. (D) Cl. caspase-1 protein levels were upregulated increasing $\mathrm{H}_{2} \mathrm{O}_{2}$ concentrations, as demonstrated by western blot analysis. (E) RT-qPCR results demonstrated that relative IL-1 $\beta$ mRNA levels were increased with increasing concentrations of $\mathrm{H}_{2} \mathrm{O}_{2}$. (F) IL-1 $\beta$ protein levels were upregulated with increasing $\mathrm{H}_{2} \mathrm{O}_{2}$ concentrations, as demonstrated by western blot analysis. ${ }^{*} \mathrm{P}<0.05$, ${ }^{* *} \mathrm{P}<0.01$ and ${ }^{* * * *} \mathrm{P}<0.001$ vs. control. RT-qPCR, reverse transcription-quantitative polymerase chain reaction; Cl., cleaved; IL, interleukin; OD, optical density; pro-, precursor.

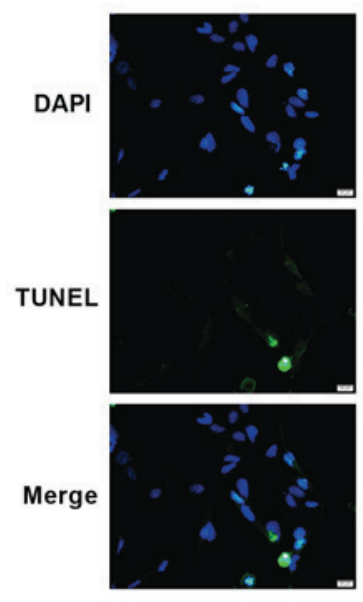

Control
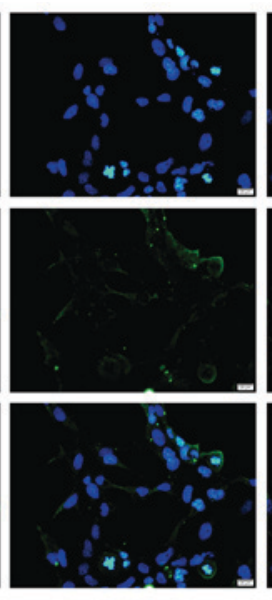

$\mathrm{H}_{2} \mathrm{O}_{2} 25 \mu \mathrm{M}$
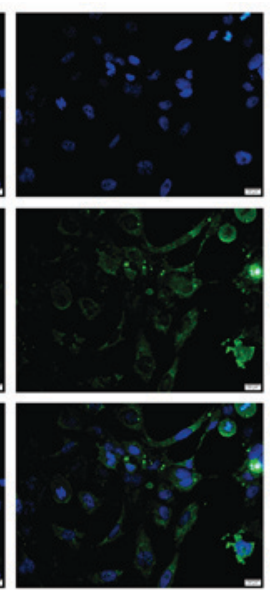

$\mathrm{H}_{2} \mathrm{O}_{2} 50 \mu \mathrm{M}$

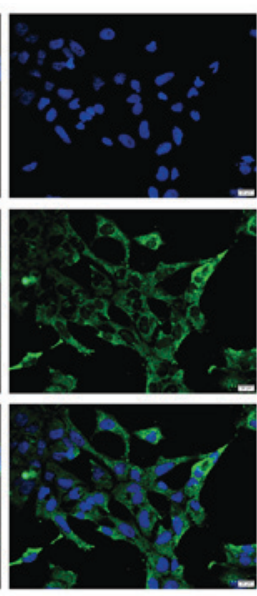

$\mathrm{H}_{2} \mathrm{O}_{2} 100 \mu \mathrm{M}$

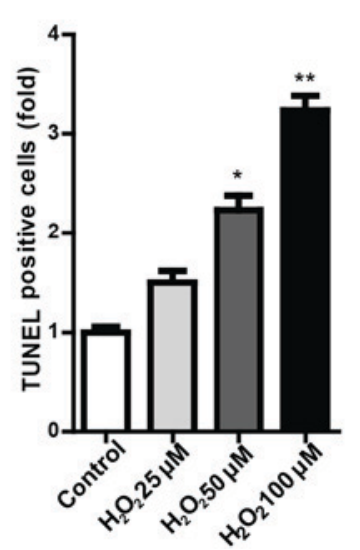

Figure 2. TUNEL staining images of SRA01/04 cells. Cells were treated with 0, 25, 50 and $100 \mu \mathrm{M} \mathrm{H}_{2} \mathrm{O}_{2}$ and TUNEL analysis was performed. Blue, nuclear staining with DAPI; green, TUNEL staining. Scale bar, $20 \mu \mathrm{m}$. 
A

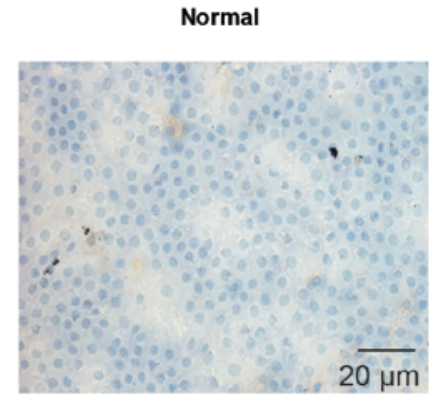

Normal

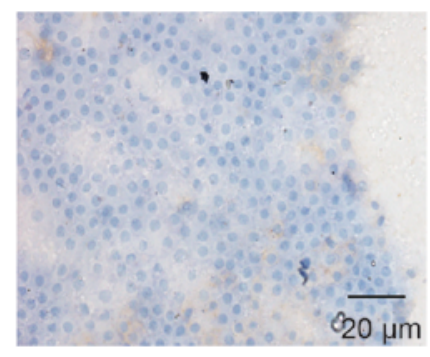

B

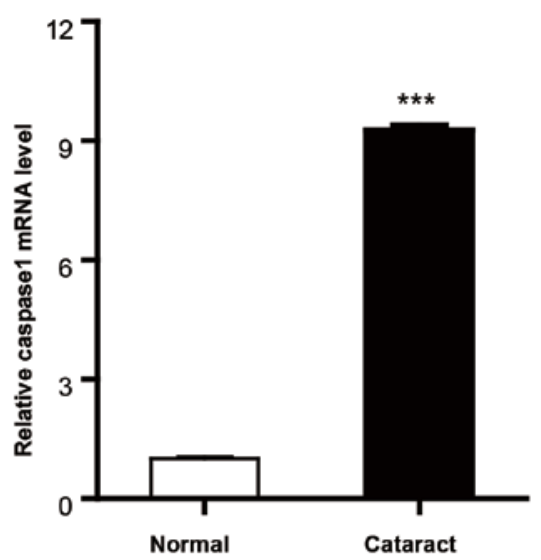

D

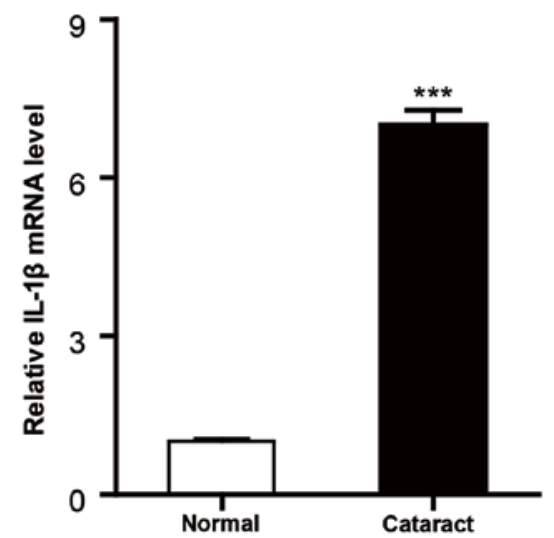

Cataract

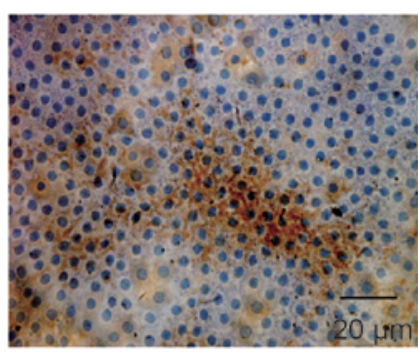

Cataract
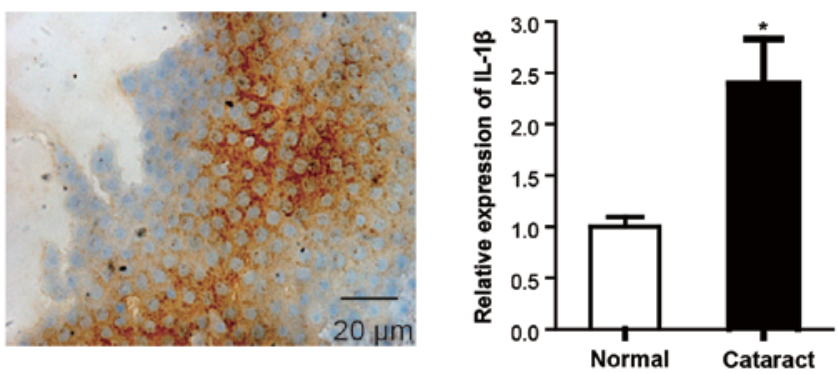

C
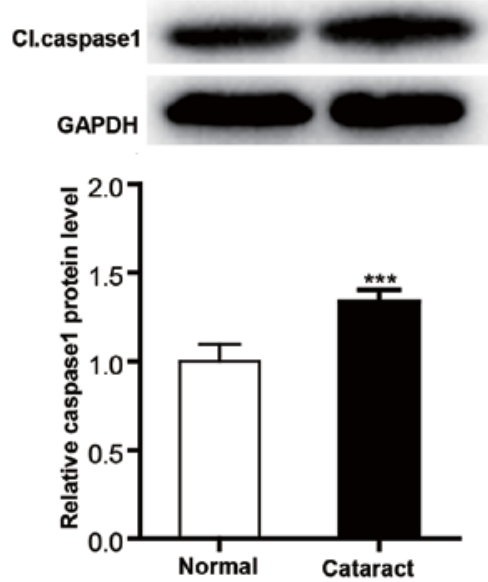

E
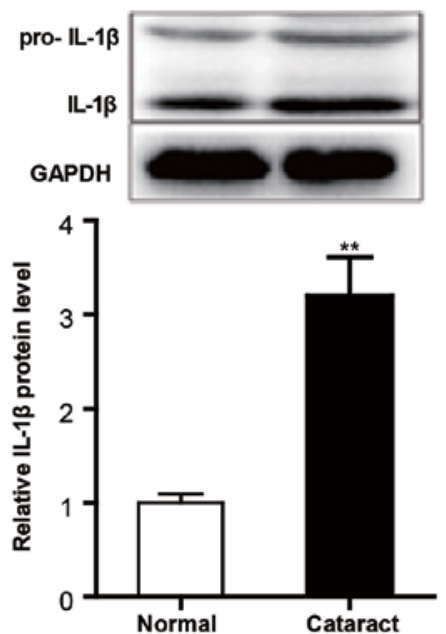

Figure 3. Validation of pyroptosis in the lens anterior capsules of patients with cataracts. (A) Immunohistochemical staining of caspase-1 and IL-1 $\beta$ in representative anterior lens capsule tissue specimens compared with normal controls. Scale bar, $20 \mu \mathrm{m}$. (B) RT-qPCR results of the relative mRNA levels of caspase-1 in anterior lens capsules of normal donors and patients with cataracts. (C) Western blot analysis of cl. caspase-1 protein levels in anterior lens capsules of normal donors and patients with cataracts. (D) RT-qPCR results of the relative mRNA levels of IL-1 $\beta$ in anterior lens capsules of normal donors and patients with cataracts. (E) Western blot analysis of IL-1 $\beta$ protein levels in anterior lens capsules of normal donors and patients with cataracts. ${ }^{*} \mathrm{P}<0.05$, ${ }^{* *} \mathrm{P}<0.01$ and ${ }^{* * *} \mathrm{P}<0.001$ vs. normal donors. IL, interleukin; RT-qPCR, reverse transcription-quantitative polymerase chain reaction; cl., cleaved; pro-, precursor. 

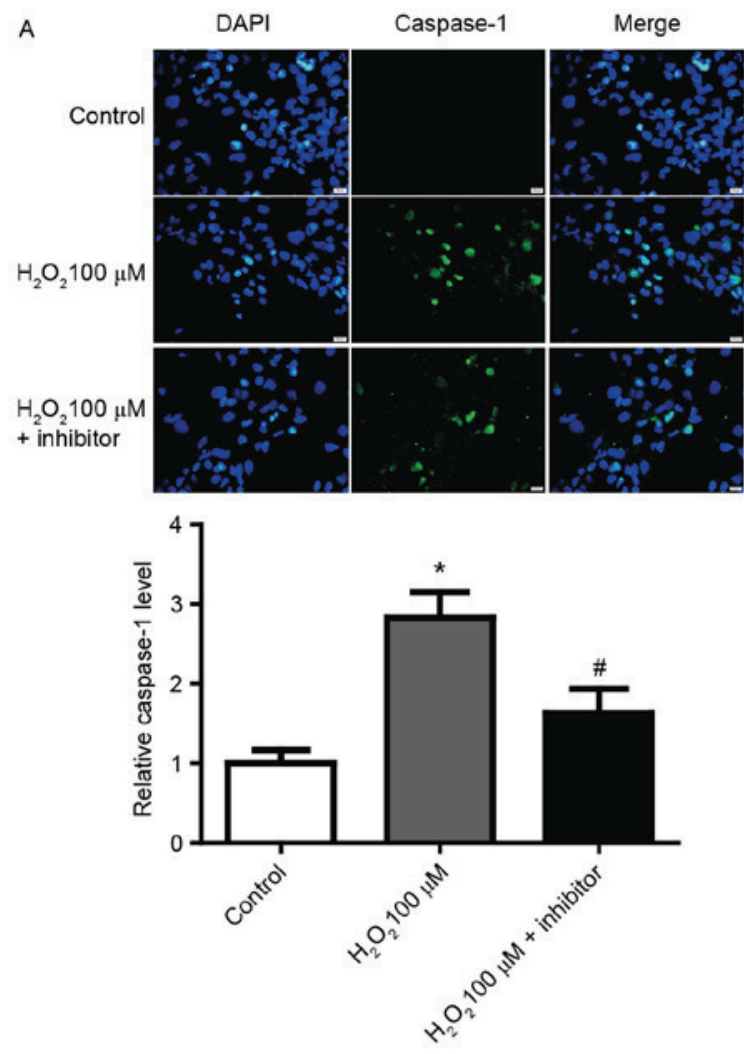

B

C
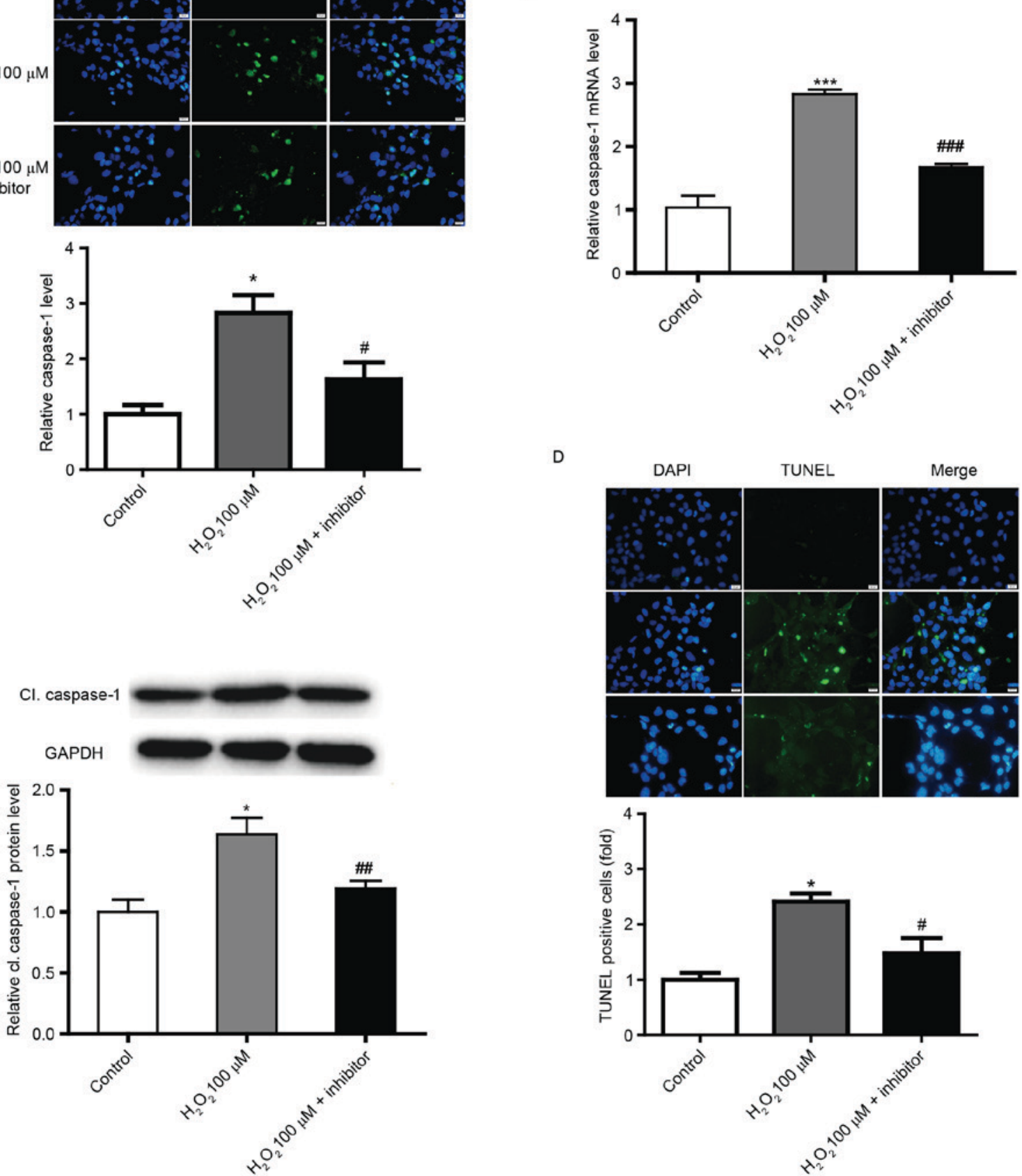

D
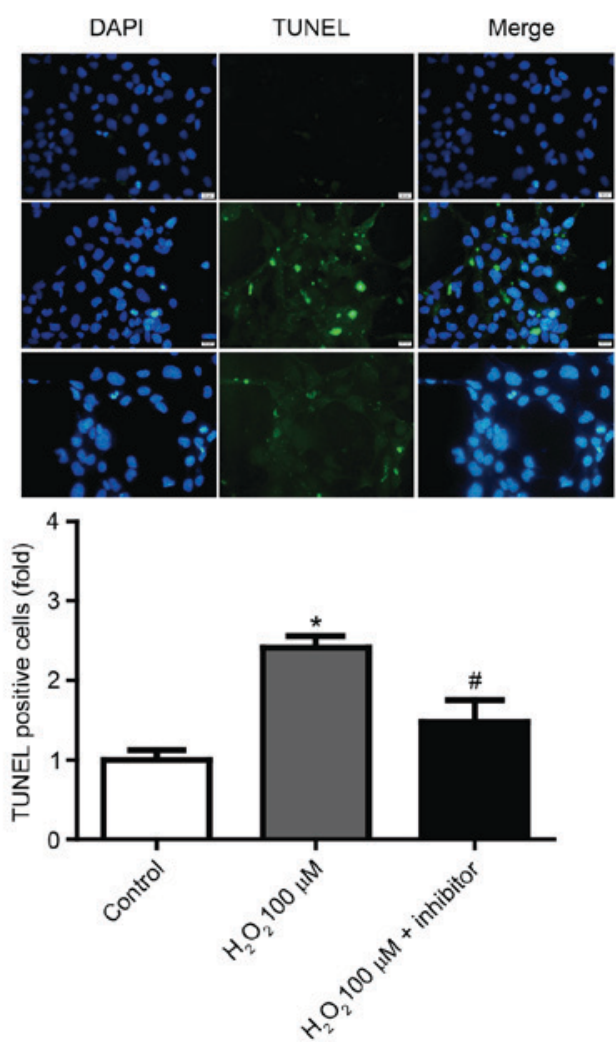

Figure 4. Downregulation of caspase-1 in human lens epithelium cells. (A) Immunofluorescence images demonstrating the expression of caspase-1 in SRA01/04 cells in control, $100 \mu \mathrm{M} \mathrm{H}_{2} \mathrm{O}_{2}$ and $100 \mu \mathrm{M} \mathrm{H}_{2} \mathrm{O}_{2}+$ caspase-1 inhibitor groups. Blue, nuclear staining with DAPI; green, caspase-1 staining. Scale

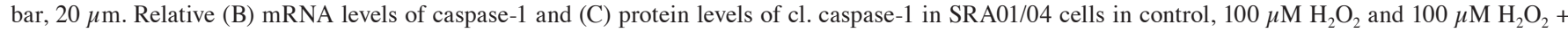
caspase-1 inhibitor groups. (D) TUNEL staining images of SRA01/04 cells in control, $100 \mu \mathrm{M} \mathrm{H}_{2} \mathrm{O}_{2}$ and $100 \mu \mathrm{M} \mathrm{H}_{2} \mathrm{O}_{2}+$ caspase-1 inhibitor groups. Blue, nuclear staining with DAPI; green, TUNEL staining. Scale bar, $20 \mu \mathrm{m}$. ${ }^{*} \mathrm{P}<0.05$ and ${ }^{* * * *} \mathrm{P}<0.001$ vs. control; ${ }^{\#} \mathrm{P}<0.05,{ }^{\# \#} \mathrm{P}<0.01$ and ${ }^{\# \# \#} \mathrm{P}<0.001 \mathrm{vs}$. $100 \mu \mathrm{M}$ $\mathrm{H}_{2} \mathrm{O}_{2}$-only group. cl., cleaved.

caspase-1 inhibitor-treated SRA01/04 cells compared with the $100 \mu \mathrm{M} \mathrm{H}_{2} \mathrm{O}_{2}$-only group (Fig. 5).

\section{Discussion}

In recent years, increasing studies have focused on understanding the mechanisms of pyroptosis in various diseases, and identifying the genes and pathways that are implicated in this process. The present study reported that pyroptosis may have an important role in human lens epithelial cells under oxidative stress. To investigate the effect of pyroptosis in cataract formation, the present study demonstrated that caspase-1 expression was increased in lens epithelium cells treated with $\mathrm{H}_{2} \mathrm{O}_{2}$. In addition, the results also confirmed that caspase- 1 
A
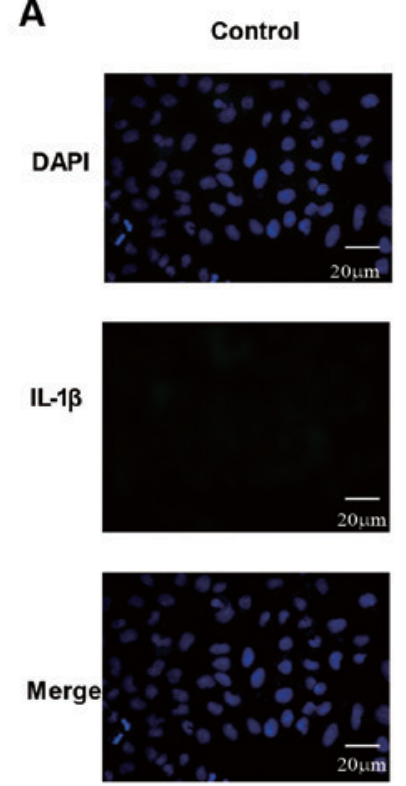

B
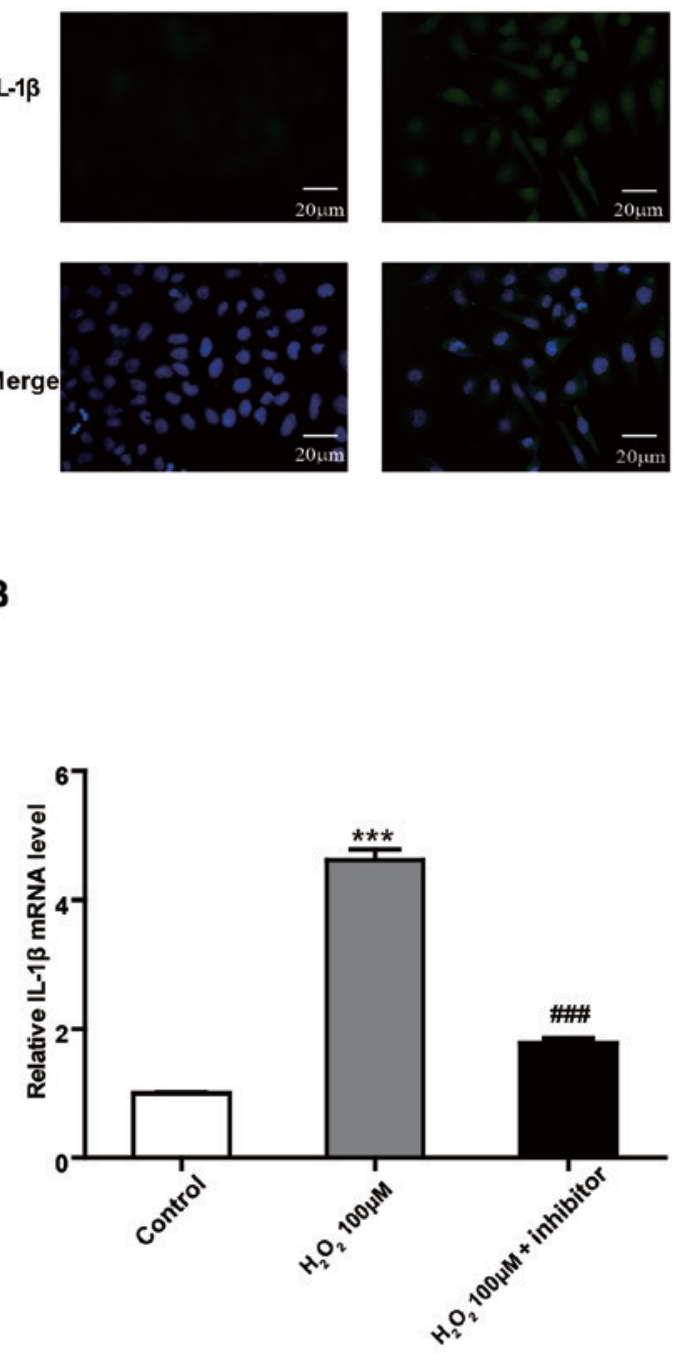
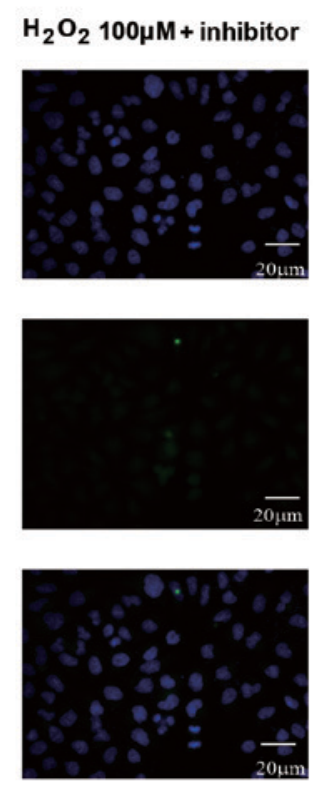

C

pro- IL-1 $\beta$

IL-1 $\beta$

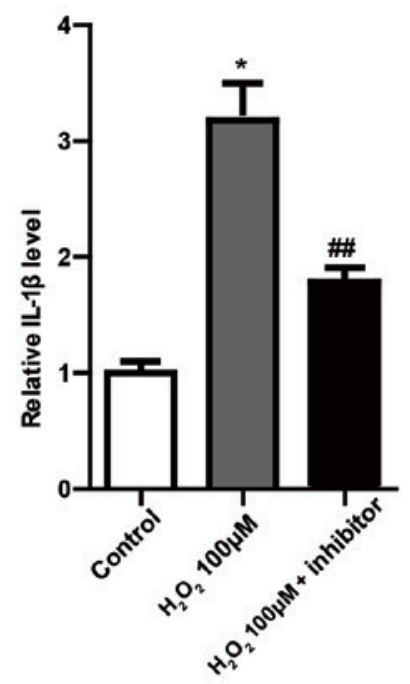

GAPDH

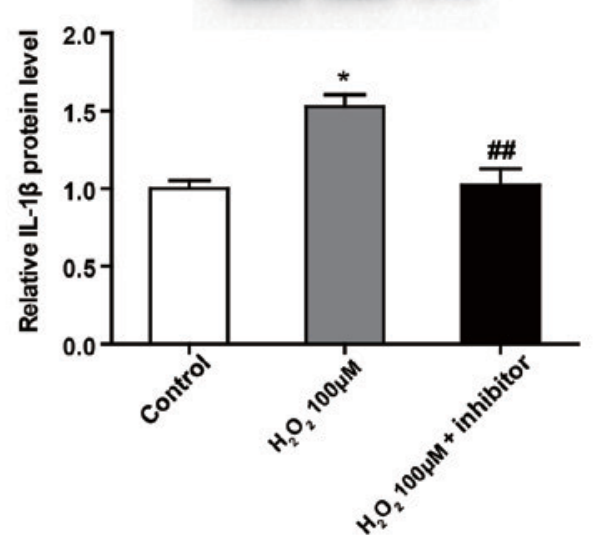

Figure 5. Caspase-1 inhibitor treatment reduced pyroptosis in human lens epithelium cells. (A) Immunofluorescence images demonstrating the expression of IL-1 $\beta$ in SRA01/04 cells in control, $100 \mu \mathrm{M} \mathrm{H}_{2} \mathrm{O}_{2}$ and $100 \mu \mathrm{M} \mathrm{H}_{2} \mathrm{O}_{2}+$ caspase-1 inhibitor groups. Blue, nuclear staining with DAPI; green, IL-1 $\beta$ staining. Scale bar, $20 \mu \mathrm{m}$. Relative (B) mRNA and (C) protein levels of IL-1 1 in SRA01/04 cells in control, $100 \mu \mathrm{M} \mathrm{H}_{2} \mathrm{O}_{2}$ and $100 \mu \mathrm{M} \mathrm{H} \mathrm{H}_{2}+$ caspase-1 inhibitor groups. " $\mathrm{P}<0.05$ and ${ }^{* * *} \mathrm{P}<0.001$ vs. control; ${ }^{\# \#} \mathrm{P}<0.01$ and ${ }^{\# \# \#} \mathrm{P}<0.001$ vs. $100 \mu \mathrm{M} \mathrm{H}_{2} \mathrm{O}_{2}$-only group. IL, interleukin; pro-, precursor.

was significantly upregulated in cataract lens anterior capsule samples compared with normal lens anterior capsule samples. Furthermore, pyroptosis was decreased when caspase-1 was downregulated by using a caspase- 1 inhibitor. Due to the relative low knockout efficiency of caspase- 1 by the inhibitor that was designed and used in the present study, certain limitations are associated with our conclusions and further experimental verification is required.

Lens epithelial cells have a key role in stabilizing the intracellular environment and maintaining a clear crystalline lens. Consistent with various other degenerative ocular diseases, cataract formation occurs when the production rate of reactive oxygen species (ROS) exceeds the removal rate $(19,20)$.
When lens epithelial cells are exposed to endogenous and exogenous oxidative stress, including growth factors, UVB radiation and inflammatory cytokines, they suffer oxidative injury and produce large amounts of ROS. Activation of ROS generation has been reported to induce NLR family pyrin domain containing 3/caspase-1 activation, which subsequently triggers IL-1 $\beta / \mathrm{IL}-18$ production and cell death by pyroptosis and apoptosis, in astroglial cells (21). $\mathrm{H}_{2} \mathrm{O}_{2}$ contains activated oxygen, which permeates cellular membranes and causes injury inside cells. $\mathrm{H}_{2} \mathrm{O}_{2}$ is commonly used for in vitro cellular oxidative damage models, such as cataract formation $(22,23)$. The present study employed $\mathrm{H}_{2} \mathrm{O}_{2}$ to investigate the effects of pyroptosis in cataracts. 
Caspase- 1 and IL-1 $\beta$ are important markers in the process of pyroptosis (24). The caspase family constitutes a family of cysteinyl aspartate proteases (25). Caspase-1 was the first caspase to be identified in mammalian cells and has an important function in apoptosis. Caspase-1 also mediates proinflammatory programmed cell death, also termed pyroptosis, in response to exogenous and endogenous stimuli to protect cells. Caspase-1 is not only activated in immune cells, but is also activated in epithelial and mesenchymal cells (26), and dysfunction of caspase-1 is closely associated with various diseases $(27,28)$. However, whether pyroptosis of lens epithelial cells is implicated in the initiation and progression of non-congenital cataracts in humans remains to be established. The results of the current study demonstrate that caspase-1 expression was increased in $\mathrm{H}_{2} \mathrm{O}_{2}$-treated lens epithelial cells in a dose-dependent manner, as determined by RT-qPCR and western blot analysis. These results were also validated in the lens anterior capsules of cataract patients compared with normal lens anterior capsule samples. Although the increased levels of caspase-1 may indicate the involvement of pyroptosis in the process, it is difficult to distinguish between apoptosis and pyroptosis as apoptosis has also been reported to be involved in cataract formation in $\mathrm{H}_{2} \mathrm{O}_{2}$-treated lens epithelial cells (29). Therefore, further studies are required to address this issue.

Caspase-1 was initially characterized as a protease that converts the inactive precursors of IL- $1 \beta$ and IL-18 (pro-IL-1 $\beta / I L-18$ ) into mature inflammatory cytokines, and was originally termed interleukin IL-1 $\beta$-converting enzyme (30). The present study also observed IL-1 $\beta$ to be downstream of caspase-1 in SRA01/04 cells. When caspase-1 inhibitor was introduced to $100 \mu \mathrm{M} \mathrm{H}_{2} \mathrm{O}_{2}$-treated SRA01/04 cells, IL-1 $\beta$ expression was markedly decreased. The superfamily of IL-1 (IL-18, IL-1 $\beta$, pro-IL-18 and pro-IL-1 $\beta$ ) are the main proinflammatory cytokines inside the cell. Activated caspase-1 leads to the activation of pro-IL-1 $\beta$, and IL-1 $\beta$ subsequently activates downstream nuclear factor- $\kappa \mathrm{B}(\mathrm{NF}-\kappa \mathrm{B})$ signaling, which enhances the release of inflammatory cytokines (31). It has been reported that NF- $\mathrm{KB}$ signaling is implicated in cataract formation (32). We hypothesize that $\mathrm{H}_{2} \mathrm{O}_{2}$-induced oxidative stress may activate NF- $\kappa \mathrm{B}$ signaling in human lens epithelial cells via caspase-1 activation and maturation of IL-1 $\beta$, which subsequently contributes to the development of cataracts. Further investigation is required to confirm this hypothesis. The authors of the present study plan to explore the association between NF- $\mathrm{\kappa B}$ signaling and pyroptosis by IL-33/sT2 signalling. IL-33 stimulation may include ERK, p38 MAPK and JNK as well as the activation of NF- $\kappa B$. It has been reported that caspase- 1 can result in the release of IL-33 (33). It may be possible for future studies to explore this phenomenon in cataracts.

In conclusion, the results of the current study provide evidence that pyroptosis participates in the oxidation of human lens epithelial cells and may be involved in the initiation and progression of non-congenital cataracts. The results indicate a potential role of pyroptosis in cataract formation, which enhances our understanding of cataracts and may provide novel effective therapeutic methods for this condition.

\section{Acknowledgements}

Not applicable.

\section{Funding}

No funding was received.

\section{Availability of data and materials}

The datasets used and/or analyzed during the current study are available from the corresponding author on reasonable request.

\section{Authors' contributions}

$\mathrm{XJ}$ analyzed and interpreted the patient data regarding the cataracts and was a major contributor in writing the manuscript. HJ and YS performed the histological examination of the lens anterior capsule samples. HZ and YG were involved in the design of the study. All authors read and approved the final manuscript.

\section{Ethics approval and consent to participate}

All samples were collected with informed consent and the study was approved by the Research Ethics Committee of Harbin Medical University.

\section{Consent for publication}

Not applicable.

\section{Competing interests}

The authors declare that they have no competing interests.

\section{References}

1. Resnikoff S, Pascolini D, Etya'ale D, Kocur I, Pararajasegaram R, Pokharel GP and Mariotti SP: Global data on visual impairment in the year 2002. Bull World Health Organ 82: 844-851, 2004.

2. Meacock WR, Spalton DJ, Boyce J and Marshall J: The effect of posterior capsule opacification on visual function. Invest Ophthalmol Vis Sci 44: 4665-4669, 2003.

3. Fernandez V, Fragoso MA, Billotte C, Lamar P, Orozco MA, Dubovy S, Willcox M and Parel JM: Efficacy of various drugs in the prevention of posterior capsule opacification: Experimental study of rabbit eyes. J Cataract Refract Surg 30: 2598-2605, 2004.

4. Fink SL and Cookson BT: Apoptosis, pyroptosis, and necrosis: Mechanistic description of dead and dying eukaryotic cells. Infect Immun 73: 1907-1916, 2005.

5. Samali A, Zhivotovsky B, Jones D, Nagata S and Orrenius S: Apoptosis: Cell death defined by caspase activation. Cell Death Differ 6: 495-496, 1999.

6. Li L, Zhao LM, Dai SL, Cui WX, Lv HL, Chen L and Shan BE: Periplocin extracted from cortex periplocae induced apoptosis of gastric cancer cells via the ERK1/2-EGR1 pathway. Cell Physiol Biochem 38: 1939-1951, 2016.

7. Li WC, Kuszak JR, Dunn K, Wang RR, Ma W, Wang GM, Spector A, Leib M, Cotliar AM, Weiss M, et al: Lens epithelial cell apoptosis appears to be a common cellular basis for non-congenital cataract development in humans and animals. J Cell Biol 130: 169-181, 1995.

8. Fan SH, Wang YY, Lu J, Zheng YL, Wu DM, Li MQ, Hu B, Zhang ZF, Cheng W and Shan Q: Luteoloside suppresses proliferation and metastasis of hepatocellular carcinoma cells by inhibition of NLRP3 inflammasome. PLoS One 9: e89961, 2014. 
9. Davis BK, Wen H and Ting JP: The inflammasome NLRs in immunity, inflammation, and associated diseases. Annu Rev Immunol 29: 707-735, 2011.

10. Yang F, Wang Z, Wei X, Han H, Meng X, Zhang Y, Shi W, Li F, Xin T, Pang Q and Yi F: NLRP3 deficiency ameliorates neurovascular damage in experimental ischemic stroke. J Cereb Blood Flow Metab 34: 660-667, 2014.

11. Li X, Du N, Zhang Q, Li J, Chen X, Liu X, Hu Y, Qin W, Shen N, $\mathrm{Xu}$ C, et al: MicroRNA-30d regulates cardiomyocyte pyroptosis by directly targeting foxo3a in diabetic cardiomyopathy. Cell Death Dis 5: e1479, 2014.

12. Hu B, Elinav E, Huber S, Booth CJ, Strowig T, Jin C, Eisenbarth SC and Flavell RA: Inflammation-induced tumorigenesis in the colon is regulated by caspase-1 and NLRC4. Proc Natl Acad Sci USA 107: 21635-21640, 2010.

13. Fann DY, Lee SY, Manzanero S, Tang SC, Gelderblom M, Chunduri P, Bernreuther C, Glatzel M, Cheng YL, Thundyil J, et al: Intravenous immunoglobulin suppresses NLRP1 and NLRP3 inflammasome-mediated neuronal death in ischemic stroke. Cell Death Dis 4: e790, 2013.

14. Chen H, Lu Y, Cao Z, Ma Q, Pi H, Fang Y, Yu Z, Hu H and Zhou Z: Cadmium induces NLRP3 inflammasome-dependent pyroptosis in vascular endothelial cells. Toxicol Lett 246: 7-16, 2016.

15. Celkova L, Doyle SL and Campbell M: NLRP3 inflammasome and pathobiology in AMD. J Clin Med 4: 172-192, 2015.

16. Isai M, Sakthivel M, Ramesh E, Thomas PA and Geraldine P Prevention of selenite-induced cataractogenesis by rutin in Wistar rats. Mol Vis 15: 2570-2577, 2009.

17. Mok JW, Chang DJ and Joo CK: Antiapoptotic effects of anthocyanin from the seed coat of black soybean against oxidative damage of human lens epithelial cell induced by $\mathrm{H} 2 \mathrm{O} 2$. Curr Eye Res 39: 1090-1098, 2014

18. Livak KJ and Schmittgen TD: Analysis of relative gene expression data using real-time quantitative PCR and the 2(-Delta Delta C(T)) method. Methods 25: 402-408, 2001.

19. Paz ML, Gonzalez Maglio DH, Weill FS, Bustamante J and Leoni J: Mitochondrial dysfunction and cellular stress progression after ultraviolet B irradiation in human keratinocytes. Photodermatol Photoimmunol Photomed 24: 115-122, 2008.

20. Babizhayev MA: Mitochondria induce oxidative stress, generation of reactive oxygen species and redox state unbalance of the eye lens leading to human cataract formation: Disruption of redox lens organization by phospholipid hydroperoxides as a common basis for cataract disease. Cell Biochem Funct 29: 183-206, 2011
21. Alfonso-Loeches S, Ureña-Peralta JR, Morillo-Bargues MJ, Oliver-De La Cruz J and Guerri C: Role of mitochondria ROS generation in ethanol-induced NLRP3 inflammasome activation and cell death in astroglial cells. Front Cell Neurosci 8: 216, 2014.

22. Zheng Y, Liu Y, Ge J, Wang X, Liu L, Bu Z and Liu P: Resveratrol protects human lens epithelial cells against $\mathrm{H} 2 \mathrm{O} 2$-induced oxidative stress by increasing catalase, SOD-1, and HO-1 expression. Mol Vis 16: 1467-1674, 2010

23. Ma T, Chen T, Li P, Ye Z, Zhai W, Jia L, Chen W, Sun A, Huang Y, Wei S and Li Z: Heme oxygenase-1 (HO-1) protects human lens epithelial cells (SRA01/04) against hydrogen peroxide (H2O2)-induced oxidative stress and apoptosis. Exp Eye Res 146: 318-329, 2016.

24. Jin X, Jin H, Shi Y, Guo Y and Zhang H: Long non-coding RNA KCNQ1OT1 promotes cataractogenesis via miR-214 and activation of the caspase-1 pathway. Cell Physiol Biochem 42: 295-305, 2017.

25. Brydges SD, Broderick L, McGeough MD, Pena CA, Mueller JL and Hoffman HM: Divergence of IL-1, IL-18, and cell death in NLRP3 inflammasomopathies. J Clin Invest 123: 4695-4705, 2013.

26. Yazdi AS, Drexler SK and Tschopp J: The role of the inflammasome in nonmyeloid cells. J Clin Immunol 30: 623-627, 2010.

27. Yang J, Zhao Y, Zhang P, Li Y, Yang Y, Yang Y, Zhu J, Song X, Jiang $G$ and Fan J: Hemorrhagic shock primes for lung vascular endothelial cell pyroptosis: Role in pulmonary inflammation following LPS. Cell Death Dis 7: e2363, 2016.

28. Zorman J, Sušjan P and Hafner-Bratkovič I: Shikonin suppresses NLRP3 and AIM2 inflammasomes by direct inhibition of caspase-1. PLoS One 11: e0159826, 2016.

29. Bai J, Yang F, Dong L and Zheng Y: Ghrelin protects human lens epithelial cells against oxidative Stress-induced damage. Oxid Med Cell Longev 2017: 1910450, 2017.

30. Fantuzzi G and Dinarello CA: Interleukin-18 and interleukin-1 beta: Two cytokine substrates for ICE (caspase-1). J Clin Immunol 19: 1-11, 1999.

31. Yang J, He F, Meng Q, Sun Y, Wang W and Wang C: Inhibiting HIF-1 $\alpha$ decreases expression of TNF- $\alpha$ and caspase-3 in specific brain regions exposed kainic acid-induced status epilepticus. Cell Physiol Biochem 38: 75-82, 2016.

32. Jia Z, Song Z, Zhao Y, Wang X and Liu P: Grape seed proanthocyanidin extract protects human lens epithelial cells from oxidative stress via reducing NF- $\mathrm{KB}$ and MAPK protein expression. Mol Vis 17: 210-217, 2011.

33. Kakkar R and Lee RT: The IL-33/ST2 pathway: Therapeutic target and novel biomarker. Nat Rev Drug Discov 7: 827-840, 2008. 